Ezzeddine, A., Shehab L., Hamzeh, F., Lucko, G. (2019). "Singularity Functions to Enhance Monitoring in the Last Planner System" In: Proc. 27th Annual Conference of the International. Group for Lean Construction (IGLC), Pasquire C. and Hamzeh F.R. (ed.), Dublin, Ireland, pp. 287-298 DOI: https://doi.org/10.24928/2019/0134. Available at: <www.iglc.net>.

\title{
SINGULARITY FUNCTIONS TO ENHANCE MONITORING IN THE LAST PLANNER SYSTEM
}

\author{
Ali Ezzeddine', Lynn Shehab² ${ }^{2}$, Farook Hamzeh ${ }^{3}$, Gunnar Lucko ${ }^{4}$
}

\begin{abstract}
Many traditionally managed construction projects suffer from schedule delays. However, in Lean Construction, the Last Planner System ${ }^{\mathrm{TM}}$ (LPS) stipulates planning tasks first at the macro (Master Schedule and Phase Schedule) and then at the micro levels (Look-ahead Planning and Weekly Work Plan, WWP) when the week of execution approaches. This paper aims to enhance the control aspect of LPS before the end of the execution in order to finish on schedule. Its objective is to improve the WWP by monitoring project progress on a daily basis to have enough time for corrective measures, catch up to the planned schedule, and minimize wastes in time and resources. The approach allows project participants to compare planned to actual progress, calculate required improvement if needed, and be alerted if cascading delays may occur. It calculates the Process Reliability Index (PRI) to check whether extra allocation of labor is needed to finish the required work, checks for congestion in work areas, and predicts the possible Percent Plan Complete (PPC) before the end of the execution week. Moreover, this paper proposes a new metric that shows the reliability of the team in applying the recommended improvements. This metric allows more realistic improvement plans compared to prior attempts. The monitoring approach can be applied to linear, repetitive, and location-based projects. Singularity functions are used as the core model because they are suitable for such schedules. They can be implemented in various computer applications. An example is used to evaluate the approach and finds it to be reliable.
\end{abstract}

\section{KEYWORDS}

Singularity functions; Last Planner ${ }^{\mathrm{TM}}$ System (LPS); Lean Construction; Percent Plan Complete (PPC); Process Reliability Index (PRI); Weekly Work Plan (WWP).

\section{INTRODUCTION}

The goal of Lean Construction is minimizing waste and optimizing value and performance (Nguyen and Waikar 2018). According to LPS, a lean production management system, project control should be based on a proactive approach that allows corrective and preventive measures

1 Masters Student, Department of Civil and Environmental Engineering, American University of Beirut, Lebanon, $\underline{\text { ame109@mail.aub.edu }}$

2 Masters Student, Department of Civil and Environmental Engineering, American University of Beirut, Lebanon, aas113@mail.aub.edu

3 Associate Professor, Civil and Environmental Engineering Dept., University of Alberta, Canada, hamzeh@ualberta.ca

4 Professor of Civil Engineering and Director, Construction Engineering and Management Program, Department of Civil Engineering, Catholic University of America, Washington, DC 20064, lucko@cua.edu 
in addition to early identification and minimization of deviations (Hamzeh et al. 2012). Several metrics are currently being used and developed in the Last Planner System to track project performance, among them are Percent Plan Complete (PPC) and Process Reliability Index (PRI). PPC tracks reliable promising at the WWP level, which is the most detailed phase of LPS (Hamzeh et al. 2012). It is calculated at the end of the execution week by measuring the percentage of tasks completed relative to those planned (Hamzeh et al. 2008). PRI is a planning index that reflects the reliability of the value of the production rates given by the crews. It compares the actual activity progress to the planned progress (González et al. 2008). PRI is measured at the activity level and has been found to function better at quantifying the said reliability than PPC (El Samad et al. 2017).

Deficiencies exist in practice, because current metrics are a reactive or "thermostat" approach to problem solving (Liker 2004), leaving no chance for corrective measures. Merely detecting a problem after it has already occurred does not facilitate improving the performance. According to Lean principles, one should pull the cord once a defect (Liker 2004) (or deviation in construction terms) is detected allowing us to take proactive measures to solve the problem before it is too late. Another gap is found in the usage of PRI, where it has not been linked to the ability of the current number of workers to finish the required work. Finally, no metric has yet been developed to reflect the reliability and ability of the project team members to apply the required improvements on a weekly level.

Improving the reliability of WWP (i.e. increasing PPC) will improve overall schedule performance (Hamzeh et al. 2012). Moreover, PPC is correlated with cost deviation, thus the higher PPC the lower the cost deviation (Formoso and Moura 2009). Hence to improve project performance, PPC will be used as a corrective metric by forecasting its value before the end of the execution week. This way, project participants can detect deviations from the planned schedule and implement corrective actions to compensate for delays. This paper also links PRI to the capacity of the current crews. Lastly, a new metric is presented for the ability of the team to implement the required improvements and actually finish executing activities on time. It aids the principle of Kaizen or continuous improvement, a pillar of the Lean philosophy.

This paper was inspired by the Lean thinking. It aims to combine proactivity with continuous improvement by early detection of deviation in order to increase the performance by the end of the execution week. This can be achieved with the aid of singularity functions that facilitate the implementation of this method. A tool was developed for this purpose. It included input cells for data collected from linear schedules, and the outputs were automatically calculated showing the forecasted PPC, required improvement in production rates, resource allocation and congestion, and the risk of the occurrence of cascading delays. Several metrics for improvement were used and developed.

To identify and minimize deviations between planned and actual progress, a need exists for an accurate tool to monitor activity performance. Singularity functions offer a mathematical solution. Their format includes parameters like activity start times and productivity rates (Lucko 2009). Singularity functions are mathematical functions known for their mathematical operator (bracket), and they were previously used for analysing internal loads in structural beams. Their application in construction management is described in the following section. 


\section{LITERATURE REVIEW}

\section{SINGULARITY FUNCTIONS}

Singularity functions offer a flexible mathematical description of discontinuous phenomena (Lucko 2007). They can be used on projects with horizontal (e.g. roads, tunnels, pipelines) and vertical (e.g. high rises, towers) geometry, and projects with longitudinal spatial or repetitive nature (Lucko 2007). Prior use in structural analysis saw singularity functions facilitate the analysis of beams under different types of loads (Beer et al. 2012). Their basic term is defined in Equation 1.

$$
\langle x-a\rangle^{n}=\left\{\begin{array}{c}
0 \text { for } x<a \\
(x-a)^{n} \text { for } x \geq a
\end{array}\right.
$$

Where $x$ is the variable under consideration, $a$ is the lower boundary of the current segment, and $n$ is the order of the phenomenon that changes at the start of the segment. If $n$ is zero, the term is a step function, but if it is one, it is a linearly growing slope. Table 1 lists various papers on their applications for the construction industry.

Table 1: Papers on Singularity Functions: Titles and Usages

\begin{tabular}{|c|c|}
\hline Title & Usage \\
\hline $\begin{array}{l}\text { Computational Analysis of Linear and } \\
\text { Repetitive Construction Project } \\
\text { Schedules with Singularity Functions } \\
\text { (Lucko 2007) }\end{array}$ & $\begin{array}{c}\text { Used for any construction project characterized by its } \\
\text { longitudinal spatial or repetitive nature, e.g. high-rise buildings, } \\
\text { highway construction, piping }\end{array}$ \\
\hline $\begin{array}{l}\text { A Unified Quantitative Model for Project } \\
\text { Management with Singularity Functions } \\
\text { (Su and Lucko 2016) }\end{array}$ & $\begin{array}{l}\text { Used for projects that are geometrically linear or repetitive in } \\
\text { their operations. Unifies schedules, cash flow, and resources } \\
\text { and transforms them from } 2 D \text { into } 3 D\end{array}$ \\
\hline $\begin{array}{l}\text { Modeling Cash Flow Profiles with } \\
\text { Singularity Functions (Lucko 2010a) }\end{array}$ & Detailed analysis of cash flows in projects \\
\hline $\begin{array}{l}\text { Spatially-Constrained Scheduling with } \\
\text { Multi-Directional Singularity Functions } \\
\text { (Lucko et al. 2014) }\end{array}$ & $\begin{array}{l}\text { Used in most projects because they all depend on the } \\
\text { available workspace within a physical location. Starts by } \\
\text { activity ordering, stacking, then finally spatial conflict } \\
\text { resolution, taking into account possible time gains }\end{array}$ \\
\hline $\begin{array}{l}\text { Work-Path Modeling and Spatial } \\
\text { Scheduling with Singularity Functions } \\
\text { (Lucko et al. 2017) }\end{array}$ & Minimizing project duration and spaces occupied by crews \\
\hline $\begin{array}{l}\text { Productivity Scheduling Method: Linear } \\
\text { Schedule Analysis with Singularity } \\
\text { Functions (Lucko 2009) }\end{array}$ & $\begin{array}{l}\text { Used for projects with horizontal (highways, tunnels, pipelines) } \\
\text { or vertical (high rises and towers) linear geometry, and } \\
\text { projects with repetitive operations. Singularity functions can be } \\
\text { used for time and amount buffers to detect the critical path } \\
\text { regarding each }\end{array}$ \\
\hline $\begin{array}{l}\text { Modeling Resource Profiles with } \\
\text { Singularity Functions (Lucko 2010b) }\end{array}$ & $\begin{array}{l}\text { Deals with optimum use of resources (primarily specialized } \\
\text { labor or equipment) by using singularity functions to level them }\end{array}$ \\
\hline
\end{tabular}

Singularity functions have advantages: They can model schedules both graphically and mathematically to facilitate the visual understanding by site personnel. They calculate finishes, can be added and subtracted, and represent varied behavior of activities over time (Lucko 2007). 
Despite the various papers published on the usage of singularity function in construction management, no research has yet been done to integrate singularity functions with project control in Lean construction within the LPS.

\section{LAST PLANNER SYSTEM}

A primary principle of the construction management process is planning and control (Alarcón and Calderón 2003). LPS aids in enhancing project performance and planning reliability. It is used by contractors to enhance on-site workforce productivity and also allows for improvements in both safety and quality (Oakland and Marosszeky 2017). LPS acknowledges the shortcomings of all forecasts, because they are always wrong: The more detailed it is, the more off it will be, and the farther it looks into the future, the less accurate it becomes (Nahmias and Cheng 2009).

LPS divides project planning into four steps. First is Master Scheduling (Should) to find the planned project duration via critical path method (CPM) calculations and sets milestones. Second is Phase Scheduling (Can) where gross constraints are identified, and reverse phase scheduling is performed. Phase scheduling links work structuring with production control (Ballard and Howell 2003). Third is Lookahead Planning (Will) that is spread over 2-6 weeks during which tasks are broken down and made ready. Fourth is the WWP (Did), where reliable promising is practiced, PPC is measured, and reasons of plan failure are acted upon (Hamzeh et al. 2009; El Samad et al. 2017). The WWP, which contains the highest level of schedule detail, should contain sound assignments that are made ready by removing any constraints that prevent them from becoming ready for execution. At this stage, learning from plan failures takes place in order to prevent their emergence in the future.

Metrics proposed by LPS aim to assess project performance by measuring anticipated tasks (TA) and tasks that are made ready (TMR). PPC is the percentage of completed tasks of those planned (Hamzeh et al. 2012): PPC = Did/Will (El Samad et al. 2017). PPC shows production planning efficiency and workflow reliability (Chitla and Abdelhamid 2003). It also indicates the reliability of the promises made, and it is related to labor productivity (Hamzeh et al. 2012). PPC is calculated at the end of the week of execution. Another metric is PRI, which is positively correlated to activity performance (González et al. 2008). PRI is the ratio of actual weekly activity progress to that forecasted: PRI = Actual Production Rate / Forecasted Production Rate. Since PRI compares actual to planned progress, an issue might arise if the plan was not optimal. Planners must ensure that the baseline that is to be met is near optimal for PRI to be relevant.

Recently, a new study by Abou-Ibrahim et al. (2019) addressed the effects of capacity planning on a project's performance. According to the study, several barriers hamper the planners' ability to accord between a crew's workload and capacity in the WWP during the lookahead planning. Two of which are (1) the planners' inability to predict the workload that can be handled by the crew and (2) the difficulty of specifying what activities will be unconstrained and ready for execution beforehand (ibid.). Load is defined as the amount of work that needs to be done in a predefined set of time, and capacity is the amount of work that crews can execute. The authors describe two types of planners; the first being informed Planners who assign weekly capacities according to their project's metrics. The second type is Un-informed Planners who assign a constant capacity for the whole project or assign the capacity through random guessing (ibid.). Informed Planners positively affect project performance on the level of project cost and schedule simultaneously. They also pay close attention while monitoring the execution of tasks to follow up with their project's metrics and to study the effect of their assigned capacities (ibid..

Several attempts to develop tools that facilitate Lean Construction concept implementations like LPS - have been made, including the Integrated Production Scheduler (Chua et al. 1999), 
which aims to achieve a schedule of quality, timeliness, and transparency (Chua et al. 1999). In the Integrated Production Scheduler, JavaBeans and XML were used to develop a scheduling model (Chua et al. 1999). A prototype called LEWIS assisted in making plans more reliable and assignments more constraint-free (Sriprasert and Dawood 2002). Newer methods of planning rely on computer simulation (Song and Eldin 2012; Taghaddos et al. 2012). Song et.al (2012) developed an adaptive real time tracking and simulation method in the attempt to enhance the lookahead phase in the LPS (Song and Eldin 2012).

The paper introduces a new practical method to the Last Planner System. The method enhances project monitoring and control at the level of the WWP by proactively calculating project measures such as actual finish dates based on the current status of the system, required improvements in production rates, worker allocation and congestion. The method also predicts the value of the PPC as the tasks progress, and a new metric is suggested to be added to the Last Planner System.

\section{METHODOLOGY}

Design Science Research (DSR) is the research methodology of this study. In construction management, DSR can be a proper tool when building problem solving objects that tackle real problems. It is considered a constructive research which connects research and practice (Rocha et al. 2012), and this is the objective of this paper. In this study, integrating LPS with a mathematical model produces a new tool for monitoring actual activities on the WWP, and this is how research (LPS and singularity functions) is connected to practice (actual activities on the WWP). It integrates singularity functions to improve and nearly optimize project performance ahead of the end of the week of execution. An example of a small location-based schedule will test the validity of the proposed monitoring approach.

The approach is based on comparing planned and actual values of task progress. Forecasted data are taken from the WWP, while field personnel collect data on the actual progress. In graphical form, it allows detecting deviations and gives quantitative values for the required increase in production rates to improve the progress by the end of the week. Here singularity functions will facilitate both visual monitoring and automatic improvement in numerical form.

The purpose of this study is to present a method for quick adjustment during execution to evaluate project progress. It suggests a proactive approach by using actual task progress to forecast PPC to prepare corrective and preventive measures for improvement. This improvement should be based on reliable values of production rates by linking required improvements to PRI. Risks of cascading delays or congestion from reallocating resources can be proactively detected by functions in the model. Using numerical examples, this paper demonstrates the functionality in different performance scenarios. It encourages project participants to use this approach to increase their performance ahead of time and monitor their crews, and thus make their promises more reliable. Finally, an evaluative metric is developed to assess the overall weekly progress.

\section{SINGULARITY FUNCTIONS FOR MONITORING AND PERFORMANCE IMPROVEMENT}

This research focuses on using metrics such as PPC and PRI to actively control any deviations from the plan. The study focuses on controlling and not scheduling a plan, so the base plan is assumed to already be done and near optimal. The process starts by entering the base plan for the weekly work plan, which includes activities to be executed and information about them such as scheduled start and end times, quantity of work that needs to be done, and the number of workers 
executing it. With only these inputs, the model with singularity functions can graphically represent the activity as a forecast.

The next step in the process is site personnel recording actual activity progress. This can be done daily during the execution of the activity, (or the first three days of each week) to leave some time for improvements if needed. To allow the singularity functions to represent the actual activity progress graphically, only three inputs are needed: The time that the activity actually started, the time at which the data was taken, and the work done up to that moment. The user can visualize the actual progress, and the function will calculate the predicted finish time based on the actual productivity of the crew. At this point, the model automatically detects future cascading delays occurring if an activity is behind schedule and will affect its succeeding activities.

Singularity functions can quantify the needed improvement in the production rate to finish at a desired time. The user specifies said time, and the function automatically gives the required production rate needed to finish the activity on the desired time. For example, for an activity with a planned duration of 4 days and required work of 4 units, the following improvement using singularity functions can be done as shown in Figure 1 per Equations 2 and 3.

Actual work without improvement $W_{\mathrm{n}}(t)=0 \cdot\langle t-0\rangle^{0}+1 / 2 \cdot\langle t-0\rangle^{1}-1 / 2 \cdot\langle t-8\rangle^{1}$

Actual work with improvement $W_{\mathrm{i}}(t)=0 \cdot\langle t-0\rangle^{0}+1 / 2 \cdot\langle t-0\rangle^{1}+1 \cdot\langle t-2\rangle^{1}-4 \cdot\langle t-4\rangle^{1}-3 / 2 \cdot\langle t-4\rangle^{1}(3)$

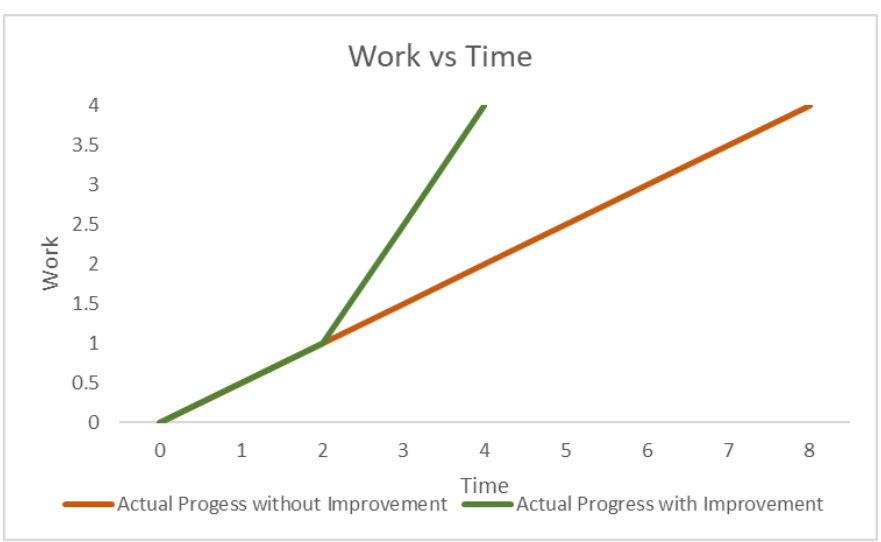

Figure 1: Graphical example of actual progress with and without improvement

(González et al. 2008) suggested the process reliability index (PRI). This new metric measures the effectiveness of planning from a commitment point of view. It is calculated by dividing the actual production rate of an activity by its forecasted production rate per Equation 4.

PRI = Actual Production Rate / Forecasted Production Rate

As already mentioned, PRI is most effective if the base plan is already optimized as this study assumes. It uses PRI to make planning more reliable. Each crew has a normal production rate for planned progress, and a maximum production rate, which reflects the crew's maximum capacity. To ensure that the crew can execute the improvement calculated by the singularity function, the required improved production rate is compared with the maximum, but with a modification per Equation 5: The modified maximum production rate is defined as the maximum production rate multiplied by PRI. This way each crew's reliability in their production rates can be considered.

Modified Maximum Production Rate = Maximum Production Rate x PRI

Then Equation 6 informs whether the crew is able to finish or must allocate extra workers. 


\section{Allocated Workers $=($ Required Improved Production Rate $/$ Productivity $)$ \\ - Current Number of Workers

Congestion in construction can occur in work areas where the number of workers in it is more than how much the area can hold (Koskela 1999). It leads to a decrease in productivity and safety on the site. Therefore, the model gives an alert to notify of any congestion risk. Congestion can occur if the number of workers needed to complete the activity on time exceeds the acceptable limit. The acceptable density is determined by the user as model input in workers $/ \mathrm{m}^{2}$.

It is now possible to calculate the percent task complete (PTC) of the actual activity that will help in forecasting the PPC. PTC is the ratio of work done at any time to the total work needed to be done. Once PTC is calculated, the functions can detect at which date the activity will reach $100 \%$ PTC, and thus it can be counted in the PPC calculation as one of several inserted activities. Note how by few inputs into this model can give users the ability to forecast the value of the PPC while they are still at mid-week. The importance of this forecast lies in two main points: One is to identify an activity that is preventing PPC from reaching a desirable value. The second is to be proactive and take corrective measures so that the actual PPC at the end of week would increase.

Lastly, the new suggested metric is the Percent Improvement Complete (PIC). It is measured at the end of the execution week to quantify the team's reliability in completing the activities that needed improvement during the week. Essentially it measures the reliability of the promises that were made during the week of execution: It is the ratio of the number of activities that required improvement and were actually completed on the required end time, to all those that required improvement (including those that were and were not completed on their required end time). PIC can be used for future improvement to assess the capability of the control system to apply required improvements to activities' production rates by removing constraints on the spot.

PIC $=$ Number of Activities That Needed Improvement and Were Completed / Number of All Activities That Needed Improvement (7)

Expressed in LPS terms, PIC = Did Improve \& Complete / Should Improve as its definition .

\section{APPLICATION EXAMPLE}

A small example is analyzed to test the proposed tool. A five-story building project consists of sequential activities A, B, and C in the WWP. The area of each floor is $300 \mathrm{~m}^{2}$ and the working area is $50 \mathrm{~m}^{2}$. Input and output are labeled in Table 2.

Table 2: Program Input and Output per Activity

\begin{tabular}{|c|c|c|}
\hline Item & Input & Output \\
\hline Forecast Activity Data & $\begin{array}{l}\text { Start time - End time - Work to be } \\
\text { done - Actual start time }\end{array}$ & Planned production rate \\
\hline Actual Activity Data (so far) & $\begin{array}{l}\text { End time before improvement } \\
\text { Work done so far }\end{array}$ & $\begin{array}{l}\text { Actual production rate - Warning } \\
\text { of any cascading delays }\end{array}$ \\
\hline Improvement of Activity & Required end time & $\begin{array}{l}\text { Required improved production } \\
\text { rate }\end{array}$ \\
\hline Resources Data & $\begin{array}{l}\text { Number of workers - Maximum } \\
\text { production rate - Working area - } \\
\text { Congestion limit }\end{array}$ & $\begin{array}{l}\text { PRI - Modified maximum } \\
\text { production rate - Warning if } \\
\text { resource allocation is needed - } \\
\text { Congestion warning }\end{array}$ \\
\hline
\end{tabular}


The output is calculated using singularity functions. For example, for activity A with a duration of 3 days (from day 0 till day 3), there are 5 units that must be done. The work started at day 0 , and 2.5 units were completed up till day 2 (actual production rate $=1.25$ units/day). In order to finish the activity at day 3 , the required improved production rate must become 2.5 units/day.

Actual work without improvement $=0 \cdot\langle t-0\rangle^{0}+1.25 \cdot\langle t-0\rangle^{1}-5 \cdot\langle t-4\rangle^{0}-1.25 \cdot\langle t-4\rangle^{1}(8)$ Actual work with improvement $=0 \cdot\langle t-0\rangle^{0}+1.25 \cdot\langle t-0\rangle^{1}+(2.5-1.25) \cdot\langle t-2\rangle^{1}-5 \cdot\langle t-4\rangle^{0}-2.5$

$$
\cdot\langle t-4\rangle\rangle^{1}
$$

The results for activity $\mathrm{B}$ show that the actual progress would cause a cascading delay. It also appears that all activities need improvement to be completed on time. Therefore, the required production rates are calculated and shown. After inserting the maximum production rate, it is modified by the PRI. Productivity is then shown after inserting the current number of workers in the crew. Since all activities show some deviation from their plan, all maximum production rates are reduced. Activities $\mathrm{B}$ and $\mathrm{C}$ require extra resource allocation, while the crew for activity $\mathrm{A}$ is sufficient. Moreover, congestion is detected in activity B if the required number of workers is added. This shows that the required production rate cannot be implemented, so the end time for B must be extended. Figure 2 shows the planned, actual, and improved progress for A, B, and C.
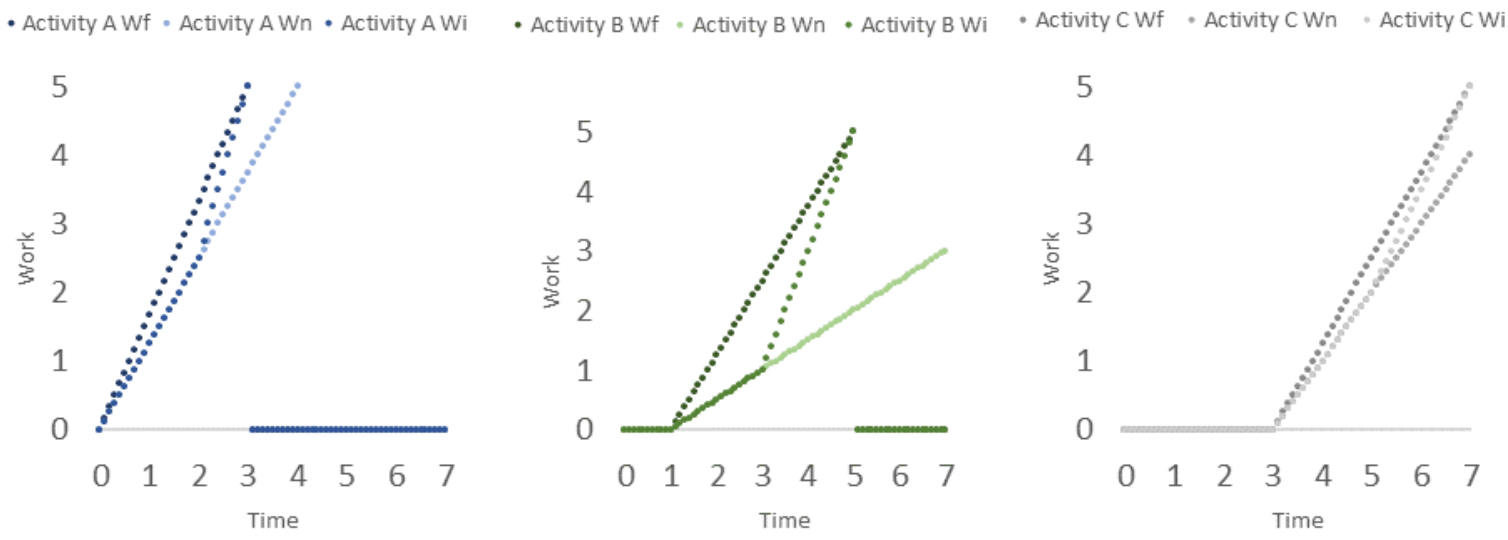

Figure 2: Forecasted, Actual, and Improved Progress for Activities A, B, and C respectively

PPC is forecasted before the end of the week at the "end time just before improvement", which allows the crew to proactively improve their progress (Table 3).

Table 3: Forecasted PPC in case no improvements were done

\begin{tabular}{ccccc}
\hline Actual No Improvement & $\begin{array}{c}\text { MAX PTC at } \\
\text { End of WWP }\end{array}$ & $\begin{array}{c}\text { Status at End } \\
\text { of WWP }\end{array}$ & $\begin{array}{c}\text { \# of Tasks } \\
\text { on WWP }\end{array}$ & PPC forecasted \\
\hline A & 100 & 100 & & $33 \%$ \\
B & 60 & 60 & 3 & \\
C & 80 & 80 & & \\
\hline
\end{tabular}


The actual value of PPC is also calculated for the end of the week of execution (Table 4).

Table 4: Actual PPC after improvements were done

\begin{tabular}{ccccc}
\hline Actual with Improvement & $\begin{array}{c}\text { MAX PTC at End } \\
\text { of WWP }\end{array}$ & $\begin{array}{c}\text { Status at End of } \\
\text { WWP }\end{array}$ & $\begin{array}{c}\text { \# of Tasks } \\
\text { on WWP }\end{array}$ & PPC \\
\hline A & 100 & 100 & & \\
B & 100 & 100 & 3 & $100 \%$ \\
C & 100 & 100 & & \\
\hline
\end{tabular}

Finally, the value of PIC is $67 \%$, meaning that only $67 \%$ of the activities that were supposed to be improved were actually completed (Table 5).

Table 5: PIC value

\begin{tabular}{ccc}
\hline $\begin{array}{c}\text { \# of Tasks that need } \\
\text { Improvement }\end{array}$ & $\begin{array}{c}\text { \# of Tasks that need } \\
\text { Improvement + can be } \\
\text { completed }\end{array}$ & $\begin{array}{c}\text { Percent Improvement } \\
\text { Complete (PIC) }\end{array}$ \\
\hline 3 & 2 & $67 \%$ \\
\hline
\end{tabular}

\section{CONCLUSION AND FUTURE RESEARCH}

This paper has presented an approach and tool to monitor project performance at the level of the WWP of LPS. Previous research used singularity functions to construct linear schedules. Yet this study uses them to monitor and forecast activity progress. It offers a user-friendly tool that fits within the existing LPS philosophy and simple enough for most site personnel to understand. The tool has shown its accuracy in calculating the required data. Moreover, it does not have limitations on the number of activities that can be entered. Several metrics from the LPS are used in this research. The PPC is forecasted from actual activity progress during the execution week to show early signs of the reliability of the look ahead planning. The second metric is the PRI, which is used as a modification factor for the maximum production rate to calculate the resource allocation. A new metric is suggested, which is the PIC for the reliability to implement required improvements during execution. It is recommended that PIC is used along with the maximum production rates that are modified by PRI to ensure that the required improvements are rational and within the crew's capacity. While PPC shows the reliability of the promises made at the level of the WWP, PIC shows the reliability of the promises made during the week of execution when the improvements were promised to be done. Additional metrics can be developed showing the volume of improvement that was done by calculating the difference between old and new production rates for each activity and coupling it with the percent of completion. New metrics can be used along with PIC to show a more refined assessment regarding production rates.

This method should be tested on an actual project as a case study and refinements could be made. Improvements in the production rates should be linked to Takt Time for all the activities. Takt Time helps ensure a standardized schedule by preventing variations in production rates. Further developments could transform the current computer implementation into an interactive mobile application that offers more lean features to facilitate monitoring and controlling process. 


\section{REFERENCES}

Abou Ibrahim, H., Hamzeh, F. R., Zankoul, E., Soren Lindhard, and Rizk, L. (2019), "Understanding the Planner's Role in Lookahead Production Planning “, Production Planning and Control, DOI: 10.1080/09537287.2018.1524163

Alarcón, L. F., Calderón, R. (2003). "A production planning support system for construction projects." Proc. $11^{\text {th }}$ Ann. Conf. Int. Group for Lean Constr., 2003.

Ballard, H. G., and Howell, G. A. (2003). "An update on Last Planner." Proc. $11^{\text {th }}$ Ann. Conf. Int. Group for Lean Constr., 22-24.

Beer, F. J., Johnston, E. R., DeWolf, J. T., Mazurek, D. F. (2014). Mechanics of Materials. $7^{\text {th }}$ ed., McGraw-Hill, NY.

Chitla, V. R., Abdelhamid, T. S. (2003). "Comparing process improvement initiatives based on percent plan complete and labour utilization factors." Proc. $11^{\text {th }}$ Ann. Conf. Int. Group for Lean Constr., 2003.

Chua, D. K., Jun, S. L., Hwee, B. S. (1999). "Integrated production scheduler for construction look-ahead planning." Proc. $7^{\text {th }}$ Ann. Conf. Int. Group for Lean Constr., 287-298.

El Samad, G., Hamzeh, F., Emdanat, S. (2017). "Last Planner System - the Need for New Metrics." Proc. 25 th Ann. Conf. Int. Group for Lean Constr., 637-644.

Formoso, C. T., Moura, C. B. (2009). "Evaluation of the impact of the Last Planner System on the performance of construction projects." Proc. $17^{\text {th }}$ Ann. Conf. Int. Group for Lean Constr., 153-164.

González, V., Alarcón, L. F., Mundaca, F. (2008). "Investigating the relationship between planning reliability and project performance." Production Planning and Control, 19(5), 461474.

Hamzeh, F. R., Ballard, H. G., Tommelein, I. D. (2012). "Rethinking Lookahead Planning to Optimize Construction Workflow." Lean Construction Journal, 2012, 15-34.

Hamzeh, F. R., Ballard, H. G., and Tommelein, I. D. (2009). "Is the Last Planner System applicable to design? - A case study. "Proc. $17^{\text {th }}$ Ann. Conf. Int. Group for Lean Constr., 1319.

Hamzeh, F. R., Ballard, H. G., Tommelein, I. D. (2008). "Improving construction workflow-the connective role of lookahead planning." Proc. $16^{\text {th }}$ Ann. Conf. Int. Group for Lean Constr., 635-646.

Koskela, L. (1999). "Management of production in construction: a theoretical view." 1999.

Liker, J. K. (2004). "The Toyota Way - 14 Management Principles from the World's Greatest Manufacturer." McGraw Hill, NY.

Lucko, G. (2007). "Computational analysis of linear and repetitive construction project schedules with singularity functions." Proc. Int. Workshop Comp. Civ. Eng., 9-17.

Lucko, G. (2009). "Productivity scheduling method: Linear schedule analysis with singularity functions." J. Constr. Eng. Mgmt., 135(4), 246-253.

Lucko, G., Cooper, J. P. (2010). "Modeling Cash Flow Profiles with Singularity Functions." Proc. Construction Research Congress, 1155-1164.

Lucko, G. (2010). "Modeling Resource Profiles with Singularity Functions." Proc. Construction Research Congress, 1165-1174.

Lucko, G., Said, H. M. M., Bouferguene, A. (2014). "Spatially Constrained Scheduling with Multidirectional Singularity Functions." Proc. Construction Research Congress, 1448-1457.

Lucko, G., Isaac, S., Su, Y., Dagan, D. (2017). "Work-Path Modeling and Spatial Scheduling with Singularity Functions." J. Comput. Civ. Eng., 31(4), 04017008(14). 
Nahmias, S., Cheng, Y. (2009). Production and Operations Analysis. $6^{\text {th }}$ ed., McGraw Hill/Irwin, NY.

Nguyen, T. Q., Waikar, S. S. (2018). "A Relook at Plan Reliability Measurements in Lean Construction and New Metrics from Digitized Practical Implementation" Proc. $26^{\text {th }}$ Ann. Conf. Int. Group for Lean Constr., 1037-1046.

Oakland, J., Marosszeky, M. (2017). Total construction management: Lean quality in construction project delivery. Routledge, 121-129.

Rocha, C. G. D., Formoso, C., Tzortzopoulos, P., Koskela, L., Tezel, A. (2012). "Design Science Research in Lean Construction: Process and Outcomes." 2012.

Sriprasert, E., Dawood, N. (2002). "Next generation of construction planning and control system: the LEWIS approach." eWork and eBusiness in Architecture, Engineering and Construction, p. 175.

Su, Y., Lucko, G. (2016). "A Unified Quantitative Model for Project Management with Singularity Functions.” Proc. Construction Research Congress, 2019-2028. 
Ezzeddine, A., Shehab L., Hamzeh, F., Lucko, G

Proceedings IGLC - 27, July 2019, Dublin, Ireland 